\title{
Review Article \\ Future of the Renal Biopsy: Time to Change the Conventional Modality Using Nanotechnology
}

\author{
Hamid Tayebi Khosroshahi, ${ }^{1}$ Behzad Abedi, ${ }^{2}$ Sabalan Daneshvar,,3 \\ Yashar Sarbaz, ${ }^{4}$ and Abolhassan Shakeri Bavil ${ }^{5}$ \\ ${ }^{1}$ Department of Internal Medicine, Tabriz University of Medical Sciences, Tabriz, Iran \\ ${ }^{2}$ Medical Bioengineering Department, School of Advanced Medical Sciences, Tabriz University of Medical Sciences, Tabriz, Iran \\ ${ }^{3}$ Faculty of Electrical and Computer Engineering, University of Tabriz, Tabriz, Iran \\ ${ }^{4}$ School of Engineering-Emerging Technologies, University of Tabriz, Tabriz, Iran \\ ${ }^{5}$ Department of Radiology, Tabriz University of Medical Sciences, Tabriz, Iran
}

Correspondence should be addressed to Behzad Abedi; behzad.abedi1993@gmail.com and

Sabalan Daneshvar; daneshvar@tabrizu.ac.ir

Received 1 August 2016; Revised 20 December 2016; Accepted 5 January 2017; Published 19 February 2017

Academic Editor: Richard H. Bayford

Copyright (C) 2017 Hamid Tayebi Khosroshahi et al. This is an open access article distributed under the Creative Commons Attribution License, which permits unrestricted use, distribution, and reproduction in any medium, provided the original work is properly cited.

At the present time, imaging guided renal biopsy is used to provide diagnoses in most types of primary and secondary renal diseases. It has been claimed that renal biopsy can provide a link between diagnosis of renal disease and its pathological conditions. However, sometimes there is a considerable mismatch between patient renal outcome and pathological findings in renal biopsy. This is the time to address some new diagnostic methods to resolve the insufficiency of conventional percutaneous guided renal biopsy. Nanotechnology is still in its infancy in renal imaging; however, it seems that it is the next step in renal biopsy, providing solutions to the limitations of conventional modalities.

\section{Introduction}

Current renal biopsy methods mostly involve automated biopsy gun and real-time ultrasound-guided technique. The diagnostic accuracy of renal biopsy depends on the different parameters such as experience of the operator, mean number of glomeruli in specimen, and extent of renal involvement [1]. Unfortunately, the conventional renal biopsy method often has several limitations that include the following. (1) Imaging-guided biopsy is an invasive and operator procedure dependent [2]. (2) There is a considerable risk of hematuria and hematoma during and after biopsy procedure $[1,3]$. (3) Pathological examination of biopsy specimen is time consuming and can take several days to complete and need expert renal pathologist [4]. (4) Either computed tomography (CT) or ultrasound should be employed for guiding the biopsy needle towards the kidney using real-time image acquisition. CT-scan can determine the exact position of the biopsy needle in relation to the renal position, but this imaging technique exposes the patients to the considerable radiation. In contrast, ultrasound guidance is a nonionizing technique for needle guiding; however, some problems like poor needle visibility, especially in obesity patients, has limited its use [2]. (5) Kidney biopsy is associated with local pain in needle penetration site and renal capsule. (6) It is important to determine the optimal size of needle due to its effect on specimen size. The mean diameter of a typical glomerulus is 100 to $250 \mu \mathrm{m}$. Therefore, the needles with diameter more than 600 um can collect high numbers of glomeruli [KIM], while increasing the renal biopsy complications such as hematuria and merely leading to the renal loss [5]. In contrast, the needles with diameter less than $400 \mu \mathrm{m}$ have a fewer side effects, while are unable to collect a sufficient number of glomerulus and the collected ones are usually fragmented or lost [6]. (7) In practice, usually more than one biopsy pass is required to obtain the desired result that increase the risk 
TABLE 1: The main milestones of the renal biopsy in last century.

\begin{tabular}{lcc}
\hline Stage & Year & Reference(s) \\
\hline $\begin{array}{l}\text { First renal biopsy } \\
\text { First radiography-guided percutaneous }\end{array}$ & 1901 & {$[2]$} \\
renal biopsies & 1944 & {$[2]$} \\
$\begin{array}{l}\text { Cutting needle } \\
\text { Percutaneous renal biopsy under direct }\end{array}$ & 1954 & {$[9]$} \\
$\begin{array}{l}\text { radiology control } \\
\text { Ultrasonic localization for renal biopsy }\end{array}$ & 1974 & {$[10]$} \\
$\begin{array}{l}\text { Using the automated biopsy gun with } \\
\text { real-time ultrasound for native renal biopsy }\end{array}$ & 1979 & {$[12]$} \\
$\begin{array}{l}\text { Spring-loaded, automated, cutting-needle } \\
\text { biopsy }\end{array}$ & $1980 \mathrm{~s}$ & {$[1]$} \\
\hline
\end{tabular}

of biopsy [1]. (8) The recovery phases of renal biopsy consist of an inpatient period of 1 to 3 days and the outpatient period of about one week [3]. (9) Usually, renal involvement is not homogeneous; therefore, small specimen cannot represent the real condition of kidney and conventional renal biopsy method is not always a reliable indicator for the overall condition of the kidney [7]. As described, renal biopsy is an invasive method and its use is limited by low diagnostic accuracy due to local evaluation of the renal parenchyma. Small number of glomeruli cannot be the representative of one million nephrons. In other words, it seems that making a medical decision based on renal biopsy results may be misleading and can result in over- or undertreatment of the patients. It has been established that " $12 \%$ of the biopsies did not shed light on the diagnosis and were unhelpful in patient management, another $11 \%$ were nondiagnostic, and an additional $1.5 \%$ failed to yield enough tissue for examination" [8]. In the recent years, several different practical techniques have been proposed to improve the efficiency of renal biopsy by using different guiding techniques and highperformance needles. The main milestones of the renal biopsy are summarized in Table 1.

This is the time to address some new diagnostic methods to resolve the insufficiency of conventional percutaneous guided renal biopsy. Several techniques have been proposed for improving the needles visibility in ultrasound-guided biopsy by increasing their echogenicity. These techniques include the use of coating agents, dimpling the needle tip, and texturing with different methods [13]. This improvement could aid accurate localizing of the needle and decrease the number of biopsy passes in order to reduce some renal biopsy complications. Despite of these advancements, as described earlier, conventional renal biopsy suffers from serious limitations. As a result, in the last decades several attempts have been made to enable clinicians to assess renal structure and function in details and to avoid the need to collect renal specimens. This can be partially accomplished either through employing the modified version of conventional imaging technologies such as pulsed ultrasonography (US), micromagnetic resonance imaging ( $\mu$-MRI) and micro-CT $(\mu$-CT) or through using multimodal approaches such as single-photon emission/CT (SPECT/CT), positron emission
tomography/CT (PET/CT), PET/MRI, and PET/optical [14]. In addition, development of different imaging contrast agents improved the diagnosis accuracy of medical imaging techniques [15]. Table 2 shows the main properties of the known medical imaging modalities including the spatial/temporal resolution of technique, operator dependency, and potential hazards to the subjects (e.g., radiation).

1.1. High-Performance US. The image quality of ultrasonography has dramatically improved in the last decades, but it has been proven that "commercial ultrasound systems lack sufficient resolution to differentiate exactly between tissue planes" [21]. The resolution of US depends on the frequency of the transducer, "frequencies between $30 \mathrm{MHz}$ and $50 \mathrm{MHz}$ provide resolution to between $100 \mu \mathrm{m}$ and $60 \mu \mathrm{m}$ respectively" [21]. In the recent years, high frequency transducer has been introduced for pushing the resolution and contrast limits of conventional ultrasonography. This method can provide an imaging depth of $50 \mathrm{~mm}$ with a spatial resolution down to $70 \mu \mathrm{m}[22,23]$. The high frequency transducer can be used as a powerful tool for diagnosing of undetectable lesions such as early detection of prostate cancer risk in rats [24]. Unfortunately, the penetration depth of high frequencies transducer is limited, and deep organs cannot be studied in their entirety [25]. To data, several studies have confirmed the efficiency of renal contrast-enhanced ultrasonography (CEUS), in early diagnosing of renal involvement [26-32]. However, CEUS is still used infrequently in clinical practice $[33,34]$. In this method, to increase the contrast of ultrasound imaging in clinical practice, shelled, gas-filled microbubbles are routinely injected intravenously to increase the mismatch in acoustic impedance between tissues and thus help detect and characterize focal lesions. Indeed, the first FDA approved contrast agent in clinical use is the $\mathrm{Gd}^{3+}$ DTPA chelate [35]. The first FDA approved contrast agent used in the US was Albunex (since discontinued) in 1994, which was only approved for echocardiology [36]. The timeline of development of US-based contrast agents has been shown in Figure 1. US contrast agents usually are air or gas filled microbubbles or microspheres that are albumin, lipid, or polymer coated [37]. In our knowledge, Definity ${ }^{\circledR}$, a C3F8filled and lipid-coated microbubble, is the first FDA-approved contrast agent for renal imaging. Ultrasound contrast agents can be divided into five different classes: (1) nonencapsulated gas microbubbles, (2) stabilized gas microbubbles, (3) encapsulated gas microbubbles, (4) microparticle suspensions or emulsions, and (5) gastrointestinal.

Tsuruoka et al. claimed that Sonazoid ${ }^{\mathrm{TM}}$ can be used as a safe efficient contrast agent in evaluation of dynamics of renal microcirculation and early diagnosing of CKD. These microbubles can improve the visualization of renal vascular by improving the echogenicity of flowing blood [38], Figure 2. These microbubbles usually have diameter between 1 and $8 \mu \mathrm{m}$ [39]. As a result these particles could not be excreted with kidney filtration. This property will help physicians in better visualization of renal microvasculature and early diagnosing of microvasculature diseases such as small vessel vasculitis and thrombotic microangiopathy. As seen in Figure 1, all of the newly developed microbubbles 
TABLE 2: Comparing the performances of different imaging modalities.

\begin{tabular}{|c|c|c|c|c|c|c|c|c|c|}
\hline & Sensitivity & $\begin{array}{l}\text { Spatial } \\
\text { resolution }\end{array}$ & $\begin{array}{l}\text { Temporal } \\
\text { resolution }\end{array}$ & $\begin{array}{l}\text { Acquisition } \\
\text { times speed }\end{array}$ & $\begin{array}{c}\text { Soft tissues } \\
\text { contrast }\end{array}$ & $\begin{array}{l}\text { Radiation } \\
\text { exposure }\end{array}$ & $\begin{array}{c}\text { General } \\
\text { anesthesia }\end{array}$ & $\begin{array}{c}\text { Operator } \\
\text { dependence }\end{array}$ & Signal used \\
\hline MRI & Low [16] & $25-100 \mu \mathrm{m}$ & $\begin{array}{l}\text { Minutes to } \\
\text { hours }\end{array}$ & Very low & High [17] & No [18] & Yes [19] & No & Radio waves \\
\hline $\mathrm{CT}$ & Low [16] & $50-200 \mu \mathrm{m}$ & Minutes & Medium & Low [20] & Yes & Yes & No & $\mathrm{X}$-ray \\
\hline US & & $\sim 1 \mathrm{~mm}$ & Second & High & High & No & No & Yes & $\begin{array}{c}\text { Mechanical } \\
\text { wave }\end{array}$ \\
\hline PET & High [16] & $1-2 \mathrm{~mm}$ & $\begin{array}{l}10 \text { seconds } \\
\text { to minutes }\end{array}$ & Medium & & Yes & No & & $\beta / \gamma$ \\
\hline SPECT & High [16] & $1-2 \mathrm{~mm}$ & Minutes & Low & & Yes & No & & $\Gamma$ \\
\hline
\end{tabular}

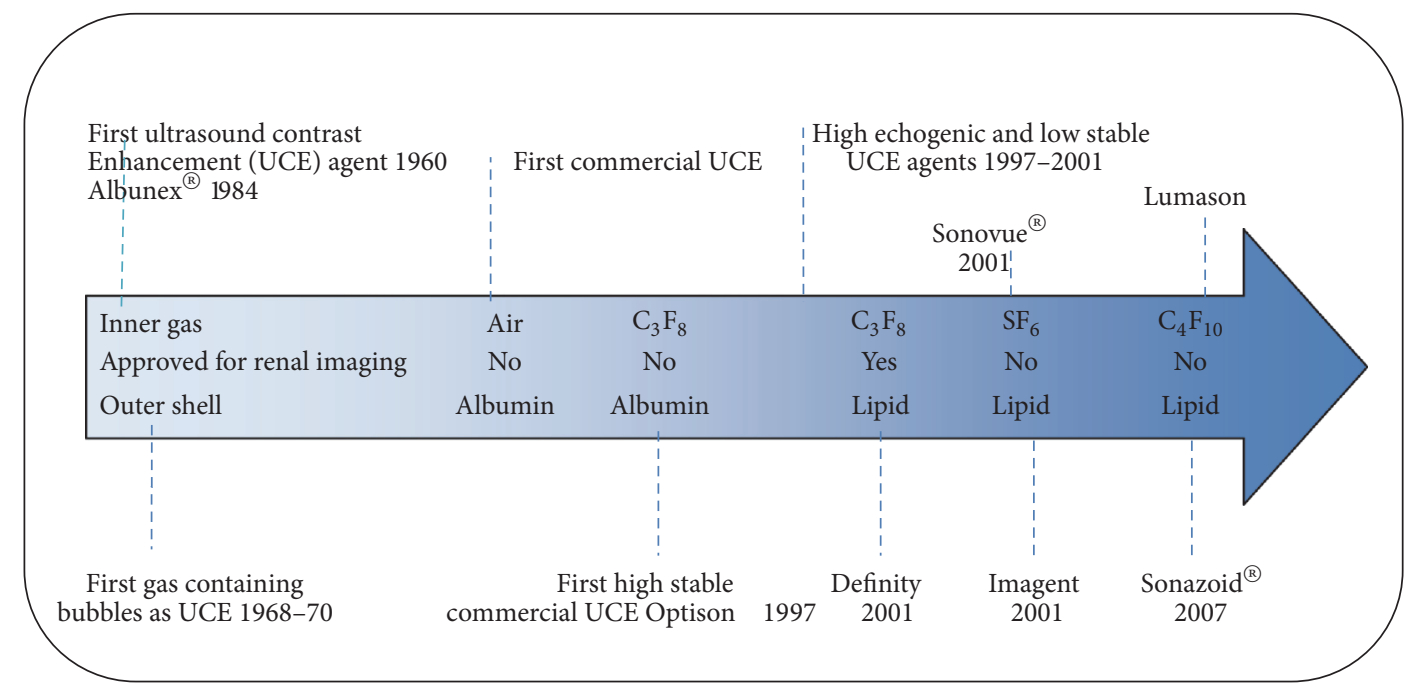

FIGURE 1: The timeline of development of US-based contrast agents.

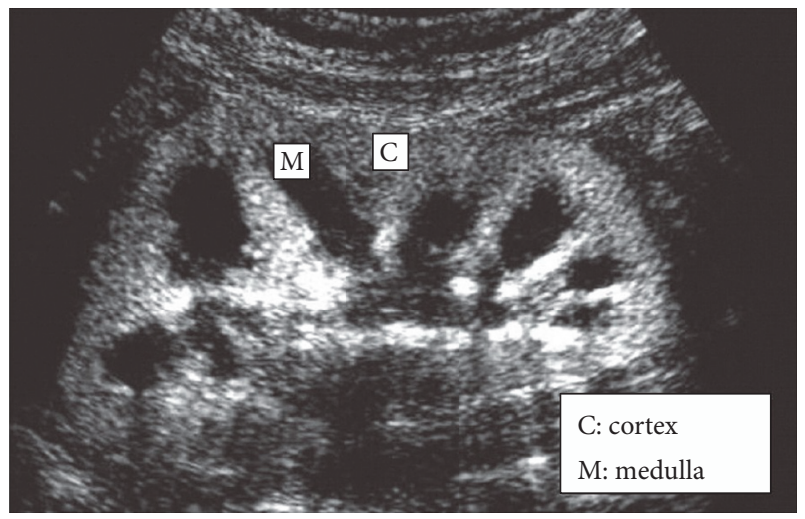

FIGURE 2: Improving the echogenicity of renal vascular employing MPs.

are lipid coated. Besides improving the general contrast of the imaging system, an ideal contrast agent needs to provide additional information about molecular and cellular content of lesion. Currently, researchers have begun to focus on the development of contrast agents with specific binding capabilities [40]. Infiltration of leukocytes in kidney parenchyma can be a potential detector for type of renal involvement. It has been established that microbubble-leukocyte interactions depend on microbubble shell composition [41]. Lipid-coated microbubbles can interact with activated leukocytes better than albumin-coated ones [42]. In our experience, this property is not enough in its own right, since an ideal sonographic contrast agent should have low affinity to tubular epithelial cells and Mesangial cells.

1.2. High-Performance CT. CT is a high-resolution method, which can characterize the mass as solid or cystic [43]. At the present time, CT is one of the most commonly used diagnostic tools in renal imaging. This method enjoys the advantage of having higher penetration depth compared to the US and, on the other hand, has higher resolution [44]. Unfortunately, CT has limited utility in imaging soft tissues such as fat/muscle, normal organ/tumors, or cortex/medulla because of similar X-ray absorption among lowdensity structures [20]. As a result, the contrast of CTbased images will be very low making the interpretation 
of the image difficult [45]. In the last decades, several attempts have been made to push the limits of CT and it seems that "its potential is only starting to be explored" [46]. High-resolution X-ray Computed Tomography (HRXCT) or microcomputed tomography ( $\mu$-CT) is one of the several $\mathrm{X}$ ray-based imaging technologies [47] which can be considered as a potential imaging modality to overcome the limitations of conventional CT. The $\mu$-CT permits noninvasive examination of gastrointestinal tract, cardiovascular system, renal tract, liver, lungs, bone, cartilage, tumorous tissue, and so forth [48]. It has been shown that $\mu \mathrm{CT}$ can be used for accurate studying of macro-to-microvascular changes during early-tolate-stage progressive renal involvement [44]. It seems the main drawback of this technique is that its resolution depends on the scan time; "it took up to 30 min to scan single maize kernels at a resolution of $13.4 \mathrm{~mm}$, whereas a two hour scan time was needed to obtain a $6 \mathrm{~mm}$ resolution" [46]. However, in medical imaging long scan time can be problematic due to the following reasons: (1) the patients will be exposed to the more dangerous high dose ionizing radiation for long time and (2) minimal movement of the subject during the imaging procedure will cause motion-blurring artifacts [49]. As a result, some patients may need anesthesia for a $\mu$-CT scan, but anesthesia is not always possible. In addition, formation of destination image can take several hours because of large data volumes. Nano-CT has been developed in order to compensate the deficiencies of the conventional $\mu$-CT [50]. Scanning time has been decreased, samples sizes increased, and resolution improved in nano-CT compared to $\mu$-CT [50]. In spite of these developments, none of these techniques is ideal for monitoring ultrastructure of renal parenchyma in itself because of the intrinsic and/or technical problems. In the recent years, several efficient exogenous CT contrast agents have been introduced for pushing back the limitations of the previously described CT-based methods. These agents usually are small iodinated molecules and barium sulfate suspensions [51]. None of these are optimal [52]. Contrastrelated acute renal injury (CI-AKI) is a serious restriction in using from small iodinated as imaging contrast agents [53]. Barium sulfate suspensions are employed only for upper gastrointestinal X-ray examinations [54]. Barium sulfate suspensions are rapid renal excretion and also known to be renaltoxic [52]. In addition iodinated agents suffer from short blood-circulation time, nonspecificity in in vivo imaging, and low contrast efficiency [52]. In the ideal situation, a large dose at a high rate would be optimal. This, however, must be weighed against safety, practicality, and cost. In the last decades, NPs have attracted great interest in bioimaging due to unique electronic, magnetic, optic, catalytic, and thermodynamic characteristics [55]. It has been established that the efficiency of each NP in CT imaging is dependent on its density and atomic number [48]. The relationship [56] between density $(\rho)$, atomic number $(Z)$, atomic mass $(A)$, Xray energy $(E)$, and X-ray absorption coefficient $(\mu)$ of each NP has been shown in

$$
\mu \approx \frac{\rho Z^{4}}{A E^{3}} .
$$

As it is clear, $\mu$ strongly depends on $Z$ [56]. In other words, NPs with high atomic number will produce more brighter signal on CT images. However, an ideal contrast agent should show high specificity toward target tissue for increasing the $\mu$ difference between the target tissue and surrounding tissue. Fortunately, the surface of these NPs can be modified with peptides, proteins, and antibodies, which make these NPs target-specific. NPs containing $\mathrm{Au}, \mathrm{Bi}, \mathrm{Ta}, \mathrm{Yb}$, and so forth can satisfy both of these requirements. Due to high $Z$, metallic NPs can provide better contrast compared to iodine NPs. Currently, research efforts are focused on the development of contrast agents that possess specific binding capabilities [40].

1.3. High Resolution MRI. MRI has the highest soft tissue contrast resolution of the imaging between all methods in use today [57]. Although MRI provides good anatomical information with appropriate resolution, it suffers from low sensitivity and temporal resolution. MRI inaccuracy results from different artifacts such as incomplete fat suppression, air bubbles in the bloodstream, and calcification [58]. This drawback can be overcome by combining MRI with other sensitive imaging modalities, such as PET, SPECT, and optical imaging [59-61]. In addition, fast MRI has been improved the spatial and temporal resolution of MRI modality, which enables the investigation of renal in detail. Ultra-high field MRI (UHF-MRI) is one of the several MRI-based imaging technologies which has been introduced as a potential technique to realize renal ideal imaging modality. Irazabal et al. employed ultra-high field MRI for assessment of polycystic kidney disease (PKD) in small rodent models of PKD [62]. One of the main advantages of the UHF-MRI is its use as a potential tool for assisting the experts to early diagnose some advanced kidney diseases such as medullary spongy kidney, medullary cystic disease, kidney malignancies in situ, and autosomal dominant polycystic kidney disease (ADPKD) [62]. ADPKD is the most common renal genetic disorder, which may not be diagnosed until ages $<20$ years using the conventional imaging modalities such as CT and US. In another example, conventional imaging modalities such as, CT, MRI, and PET cannot distinguish metastatic LN involvement, because of poor sensitivity and/or specificity and the inherent limits on size of nodal metastases that can be detected [63]. It seems UHFMRI can be employed as a powerful tool for the accurate diagnosis of ADPKD disease in early stages. However, UHFMRI cannot provide detailed information about the renal diseases in cellular levels and "another much-discussed aspect of ultra-high field imaging that has been put forward as a possible obstacle to clinical use are physiological side-effects of the magnetic field" [64]. In the recent years, several attempts have been made to compensate the drawbacks of UHFMRI. Despite these efforts, Saito et al. claimed that the image ex vivo resolution of $\mu$-CT is higher than that of UHFMRI [65]. In addition, scanning time of $\mu$-CT scanners is shorter than UHFMRI scanning systems [65]. These findings are in line with other studies; "several studies which compare the performance of $X$-ray $\mu$-CT against other imaging techniques, that is, MRI, has revealed that $X-$ ray is less costly and more convenient" [46]. As explained before, in comparison to the other imaging techniques, the 
main advantage of MRI is its excellent spatial resolution, whereas it suffers from the limited sensitivity [66]. In a simple word, conventional MRI can detect large lesions easily while it cannot detect smaller lesions due to low SNR [67]. SNR can be defined as the ratio of desired signal power to the background noise power [68]. As the size of lesions decreased, the SNR will be decreased due to low power desired signals. Magnetic nanoparticles (MNPs) have been proposed as a potential candidate for overcoming this limitation by increasing SNR. Fortunately, in the last decades, several MRI contrast agents have been introduced for improving the sensitivity of this modality. Magnavist is the first FDA approved contrast media for MRI [35]. These agents can improve the sensitivity of MRI in the early diagnosing of renal involvement [69].

As shown in Table 3, most of the FDA-approved contrast agents for MRI are gadolinium based [70]. Gadolinium itself is toxic and should be coated with other chemicals [71]. This property will help the researchers on the development of contrast agents with specific binding capabilities. Gadolinium is highly paramagnetic substance [72]. Shokrollahi divided the MRI contrast agents into two categories paramagnetic compounds, including lanthanides like gadolinium, and super-paramagnetic magnetic nanoparticles such as iron oxides [66]. Unfortunately, gadolinium based contrast agents cannot be used in patients with low glomerular filtration rate (GFR) because of the risk of NSF [70]. Iron oxide MNPs are FDA-approved contrast that are nontoxic at a low dose [73]. It has been proven that NP-based MRI can be used as a powerful tool in diagnosing acute renal failure (ARF) [74] before the serum creatinine even begins to rise [75]. Gadolinium based contrast media are classified as T1 agents, while ferromagnetic large iron oxide media are known as T2 agents [76]. SPIOs can penetrate cells. From the standpoint of clinical diagnosis and cellular imaging, the image contrast produced by such agents is far less desirable than that by the T1 agents. Magnetic particle imaging (MPI), an emerging tomographic imaging method, directly measures the magnetization of iron oxide nanoparticle tracers. The MPI signals derived from the nonlinear remagnetization response of super paramagnetic iron oxide nanoparticles (SPIONs) to an oscillating magnetic field. Efforts to propel MPI forward as an imaging method by improving its spatial resolution, imaging speed, and sensitivity have expanded [16]. Magnetic particle spectroscopy (MPS) has been developed in parallel with the reconstruction of the MPI scanners to allow researchers to evaluate, characterize, and optimize the properties of tracers at a faster pace and lower costs, independent of the confounding complexities of the hardware and software technologies of a 3D MPI scanner.

1.4. Optical Imaging. Optical imaging is a potential technique, which allows physiological and pathological activities to be studied in vivo. This modality has been introduced as a potential tool for studying the renal involvement in cellular level [102]. This method is widely used because it is both high performance and cost effective [103]. Recent development in optical imaging offers a myriad of procedures, which are useful for studying the structure and function of different organs such as kidney, brain, and colon [104].
For example, multiphoton microscopy (MPM) can provid real-time movies of the renal function in vivo without damaging tissue [105]. Despite of recent developments, optical imaging modalities suffer from some limitations such as low penetration depth. The process that limits the imaging depth and contrast of NIR imaging is scattering rather than absorption. In addition, the contrast resolution of modalities will be degraded at higher depth due to light scattering $[106,107]$. In the recent years, several procedures have been proposed to overcome the penetration depth limitation of optical imaging. Wang et al. claimed that both the depth and the contrast optical imaging can be enhanced by the application of agents [108]. Higher concentration of agents causes more water loss of skin tissue and a stronger optical clearing effect. Taruttis et al. claimed that this problem can "be overcome by adding ultrasound detection to optical excitation in exploitation of the photoacoustic effect" [106]. Photoacoustic (PA) combines the high resolution of US with the high contrast of optical imaging techniques. PA can be used for molecular visualization of kidney due to its high tissue penetration and appropriate spatial resolution [100]. It has been established that endogenous contrast agents (hemoglobin and melanin) can improve the spatial resolution of PA modality in deep tissues. However, in some cases, such as solid tumors and lymph nodes, endogenous contrast agents are not available, and exogenous contrast agents should be used to overcome this problem. It has been established that CNPs based PA can provide high resolution images from in depth organs with adequate contrast. Besides this feature, GNPs also have high scattering cross-section in the red region of the spectrum. This property is crucial for development of contrast agents for optical imaging in living organisms because of light penetration depth in SPIE. Natural nanoparticles are also widely used in PA, but they have small size $(<2 \mathrm{~nm})$ and can distribute to a wide range of tissue nonspecifically. As a result, these agents cannot provide sufficient imaging contrast in the region of interest against surrounding tissue [109]. In the last decades, carbonbased nanocomposites are extensively used in PA imaging. These NPs are strong NIR absorbance and in contrast to gold NPs carbon-based NPs are nontoxic and photostable. Based on the narrative summarized above, optical imaging is still in its infancy and it seems that optical biopsy is the next step in medical imaging, providing solutions to the limitations of conventional modalities [110]. The advantages and disadvantages of small numbers of available internal imaging modalities have been summarized in Table 4 .

\section{Future Prospect: An Ideal Renal Imaging Modality}

As described in earlier sections, despite of the recent significant advances in medical imaging technology, there are still certain applications for which the conventional imaging modalities are not the suitable solution and more developments are needed in the contrast, resolution, and the penetration depth in the future [137]. Kidney is one of the key organs, which plays an important role in regulating various physiologic mechanisms. None of the conventional imaging 
TABLE 3: Different contrast agents.

\begin{tabular}{|c|c|c|c|c|}
\hline Medical imaging types & Modality & FDA approved contrast agents & Particle size & Comment(s) \\
\hline \multirow{22}{*}{ Structural } & \multirow{22}{*}{ MRI } & AMI-25 (Feridex $\left.{ }^{\mathrm{TM}}\right)$ [77] & $\sim 58 \mathrm{~nm}[78]$ & \multirow{7}{*}{$\begin{array}{l}\text { Can be used in patients with } \\
\text { CKD stages I-V or ESD }\end{array}$} \\
\hline & & Schering (Resovist ${ }^{\circledR}$ ) [79] & $\sim 21-46 \mathrm{~nm}[80]$ & \\
\hline & & OMP50 [81] & $\sim 300 \mathrm{~nm}[82]$ & \\
\hline & & Feridex (FDA cleared) [71] & $\sim 300 \mathrm{~nm}[82]$ & \\
\hline & & Ferumoxytol [83] & $\sim 300 \mathrm{~nm}[82]$ & \\
\hline & & AMI-121 (Ferumoxsil $\left.{ }^{\mathrm{TM}}\right)[81]$ & $\sim 300 \mathrm{~nm}[84]$ & \\
\hline & & Gadolinium contrast agents [85] & & \\
\hline & & Gadodiamide $\left(\mathrm{Omniscan}^{\mathrm{TM}}\right)[86]$ & & $\begin{array}{c}\text { Linear nonionic, high } \\
\text { nephrogenic systemic sclerosis } \\
\text { (NSF) risk }\end{array}$ \\
\hline & & Gadobenate (Multihance $^{\circledR}$ ) [86] & & Linear ionic \\
\hline & & Gadopentetate (Magnavist ${ }^{\circledR}$ ) [86] & & Linear ionic, high NSF risk \\
\hline & & Gadoteridol $\left(\right.$ ProHance $\left.^{\circledR}\right)[86]$ & & Macrocyclic ionic \\
\hline & & Gadofosveset (Ablavar $\left.{ }^{\circledR}\right)[86]$ & & Linear ionic \\
\hline & & Gadoversetamide (OptiMark ${ }^{\mathrm{TM}}$ ) [86] & & Linear nonionic \\
\hline & & Gadobutrol (Gadovist $\left.{ }^{\circledR}\right)[86]$ & & Macrocyclic ionic \\
\hline & & Gadoterate $\left(\right.$ Dotarem $\left.^{\circledR}\right)$ [87] & & Macrocyclic ionic \\
\hline & & Gadoxetate (Primovist ${ }^{\circledR}$ ) [87] & & Linear ionic \\
\hline & & Iron oxide MNPs [73] & & \\
\hline & & $\begin{array}{l}\text { Super paramagnetic iron oxides (SPIO) } \\
\text { [88] }\end{array}$ & & \\
\hline & & Omniscan (FDA cleared) [71] & & \\
\hline & & $3 \mathrm{He}$ (under investigation) [89] & & \\
\hline & & $\begin{array}{l}\text { Manganese dipyridoxaldiphosphate } \\
\text { (Mn-DPDP) [90] }\end{array}$ & & \\
\hline & & $\mathrm{MnCl}_{2}[91]$ & & \\
\hline \multirow{4}{*}{ Structural } & \multirow{4}{*}{ CT } & Iopromide (Ultravist ${ }^{\circledR}$ ) [92] & $\sim 200 \mathrm{~nm}[93]$ & \multirow{4}{*}{$\begin{array}{l}\text { Nonionic monomers } \\
\text { Nonionic monomers }\end{array}$} \\
\hline & & Iopamidol (Isovue 370) [94] & & \\
\hline & & Iohexol (Omnipaque 350) [95] & & \\
\hline & & Gold nanoparticles & & \\
\hline \multirow{5}{*}{ Structural } & \multirow{5}{*}{ US } & Albunex [36] & \multirow{5}{*}{$1-8 \mu \mathrm{m}[39]$} & \\
\hline & & Optison $^{\circledR}[96]$ & & \\
\hline & & Lumason $^{\circledR}[96]$ & & \\
\hline & & Definity [97] & & \\
\hline & & Imagent $^{\circledR}\left(\right.$ formerly Imavist $\left.^{\mathrm{TM}}\right)$ [98] & & \\
\hline Structural & $\begin{array}{c}\text { Multiphoton } \\
\text { microscopy (MPM) }\end{array}$ & Nanotubes [99] & & \\
\hline Structural & OCT & $\begin{array}{l}\text { To date, there are no FDA-approved } \\
\text { contrast agents for imaging with OCT. }\end{array}$ & & \\
\hline Structural & $\begin{array}{l}\text { Photo acoustic } \\
\text { imaging }[100]\end{array}$ & Clofazimine (CFZ) & & \\
\hline \multirow[t]{2}{*}{ Functional } & PET & $\begin{array}{l}\text { Compound of }{ }^{18} \mathrm{~F} \text { and natural } \\
\text { nanoparticles (lipoproteins, viruses and } \\
\text { ferritin) [101] }\end{array}$ & & \\
\hline & fMRI & Gd-DTPA & & \\
\hline \multirow{4}{*}{ Spectral } & \multirow{4}{*}{ Fluoresce } & Indocyanine green & & \\
\hline & & Fluorescein & & \\
\hline & & Agent methylene blue & & \\
\hline & & Demeclocycline & & \\
\hline
\end{tabular}


TABLE 3: Continued.

\begin{tabular}{lclll}
\hline Medical imaging types & Modality & FDA approved contrast agents & Particle size & Comment(s) \\
\hline Spectral & $\begin{array}{c}\text { Near infrared } \\
\text { absorption } \\
\text { spectroscopy }\end{array}$ & Indo Cyanine Green (ICG) & \\
\hline Spectral & $\begin{array}{c}\text { Hyperspectral } \\
\text { imaging }\end{array}$ & & \\
\hline
\end{tabular}

modalities are consistently effective in early diagnosing of renal involvement. The kidney generally lies 5 to $10 \mathrm{~cm}$ under the skin surface in nonobese people. With ease of access, the kidney is an ideal organ in which low penetration imaging modalities can be applied successfully. For researchers, the ideal imaging technique should have the spatial resolution of MRI, temporal resolution of ultrasound, and the sensitivity of PET [16]. It can be claimed that an ideal noninvasive renal imaging technique should have the following properties [138]: (1) it should be a safe, nontoxic, and low ionization imaging technique; (2) be able to obtain dynamic images with high resolution and rich contrast for assessment of single nephron function; (3) be able to provide centimeters penetration depth into biological tissue; and (4) be of acceptable cost and offer 3D fast-imaging in living subjects. In the recent decades, several attempts have been done for realization of ideal diagnostic imaging modality by promoting the MRI, CT, and US imaging techniques. However, because of the technical complexity and/or intrinsic limitations, most of the efforts were limited to the construction of advanced animals living imaging tools [65]. Fortunately, in the recent years several methods have been proposed for improving the acquisition time of new optical imaging modalities [139]. The safety is one of the primary requirements of any imaging modality. Optical, acoustic, magnetic, and low-exposure Xray based imaging modalities are safe when compared to other techniques such as multiexposure X-ray and nuclear medicine based imaging. Nevertheless, in spite of safety of these modalities, low imaging depth of penetration and/or poor resolution limits their applications. Theoretically, there is a tradeoff between imaging depth of penetration and spatial resolution in mechanical [140] or electromagnetic [141] based imaging modalities. In other words, the resolution of optical imaging modalities will be degraded at higher depth due to light scattering $[106,107]$. Therefore, beside high spatial resolution, an ideal imaging modality should have the sufficient imaging penetration depth in tissue. It seems understanding the wavelength, refractive index, Brownian motion, orientation, and size and phase function of tissue scatters can result in modern powerful medical imaging modality [120]. The penetration depth of $\sim 10$ centimeters allows complete investigation of organs such as liver, pancreas, and kidney in nonobese ones. This can be achieved in five ways. (1) It seems improving the conventional imaging technologies can help provide better understanding of internal organs. (2) Using semi-invasive methods such as optical biopsy [142], intraoperative laparoscopic ultrasound (usually 4-20 MHz), rigid or flexible probe, $[143,144]$, microultrasound probe [24], endoluminal US (usually 12-40 MHz) [145], and so forth can be helpful in accurate evaluation of internal organs such as kidney. As cleared earlier, renal involvement is not homogeneous. Therefore, some regions within the kidney can be identified as suspicious for renal involvement based on this technique and biopsy can be done to these regions. (3) The development of hybrid imaging methods such as optic/ultrasound provides greater imaging depth penetration in biological tissues and allows obtaining high resolution $3 \mathrm{D}$ images from internal organs $[8,146]$. (4) In our knowledge, depth of penetration can be considered as a common limiting factor in almost all of high resolution mechanical and electromagnetic based imaging modalities. Metamaterial lenses makes the internal organs appear closer than they actually are. This method makes in-depth imaging possible, while maintaining the high depth-to-resolution ratio. The resolution of this technique in tissue imaging was three times better than diffraction limits [147]. (5) Development of new computer algorithms will definitely help to improve the performances of different medical imaging modalities in the future [148].

As cleared, despite recent significant advances in medical imaging technologies, nonmodality has an optimal resolution and penetration depth. Despite of continuous development, most of the medical imaging theories are a vision of the future and considerable effort should be dedicated to make them true. The purpose of this paper is to introduce a strategy to guide current and future activities to achieve this vision. We hypothesise that one of the potential application areas of future imaging technologies could be in assessing kidney where imaging depth of $\sim 10$ centimeter is sufficient to evaluate early renal involvement. Based on these evidences, it can be predicted that a safe high-resolution depth imaging modalities can potentially be employed for the monitoring and diagnosing of early renal involvement [110]. This technology will decrease the need for renal biopsy and as a result can remove any side effects of the conventional renal biopsy and enabling overcoming the limitation of the conventional methods. Achieving this target will involve several phases and may require new procedures. However, any improvement in this area will benefit the performances of the conventional medical imaging modalities. The first benefit of this new nonionization modality will be the medium-resolution high depth capability to determine the exact position of the biopsy needle in relation to the renal position, allowing for minimization of the number of biopsy passes and consequently reducing the recovery period. Moreover, high-resolution medium depth modality will allow complete and accurate investigation of internal organs such as transplant kidney, liver, and pancreas in nonobese ones. 


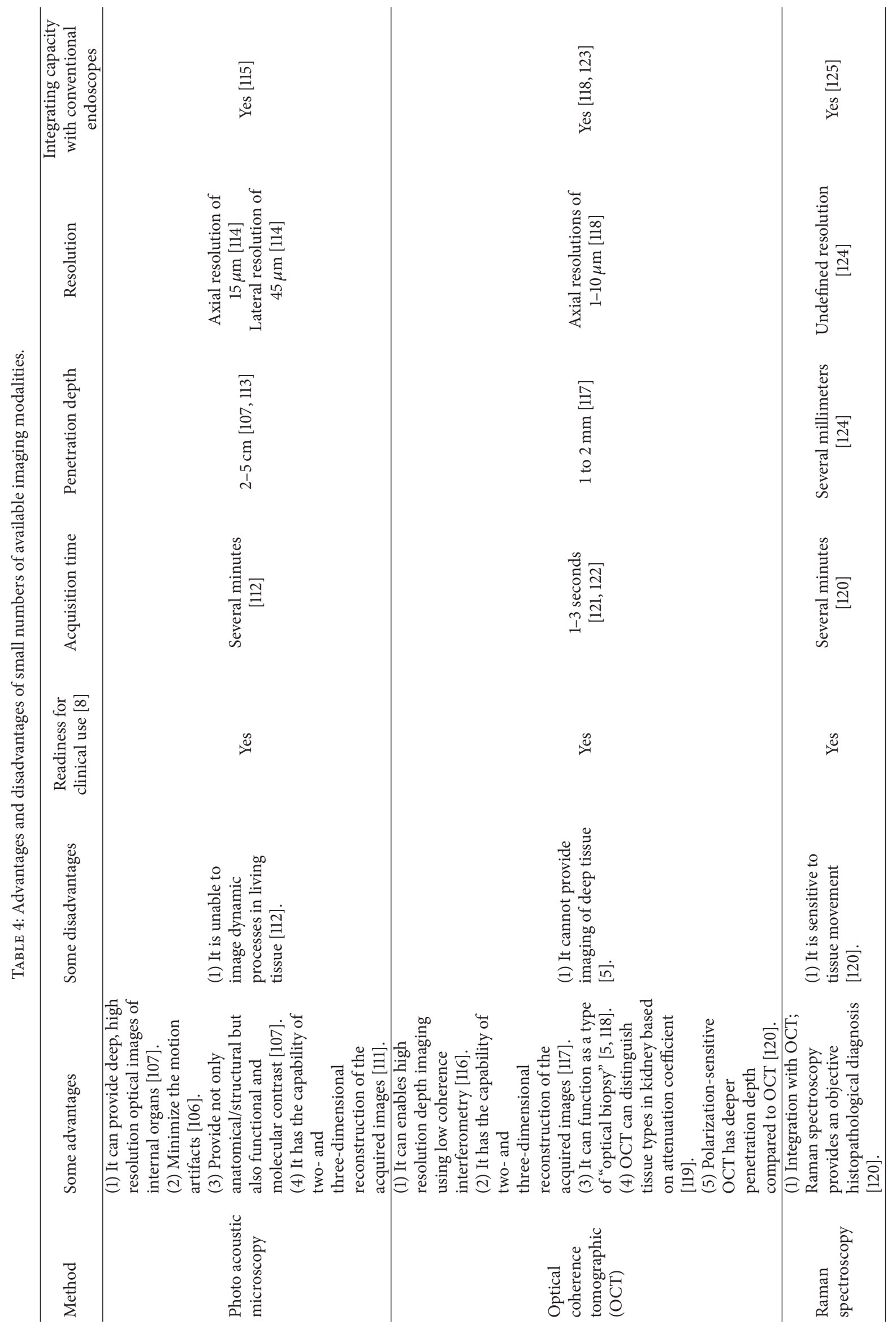




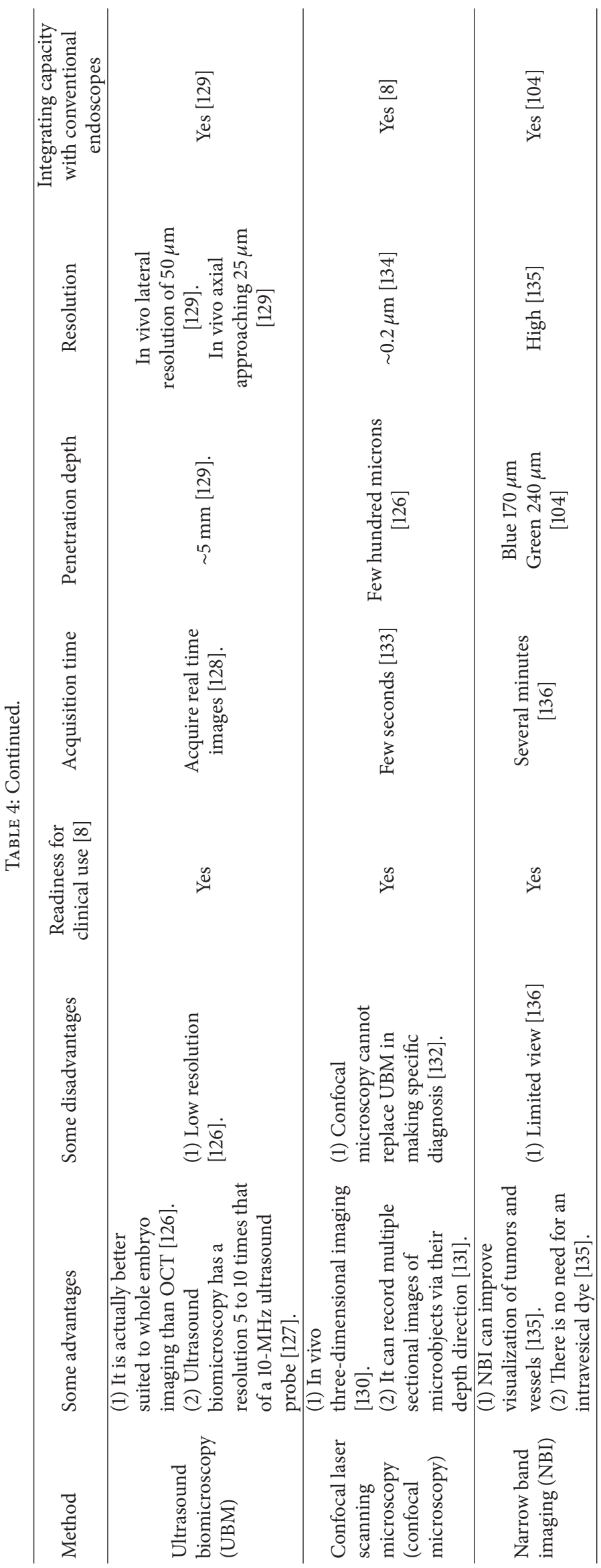




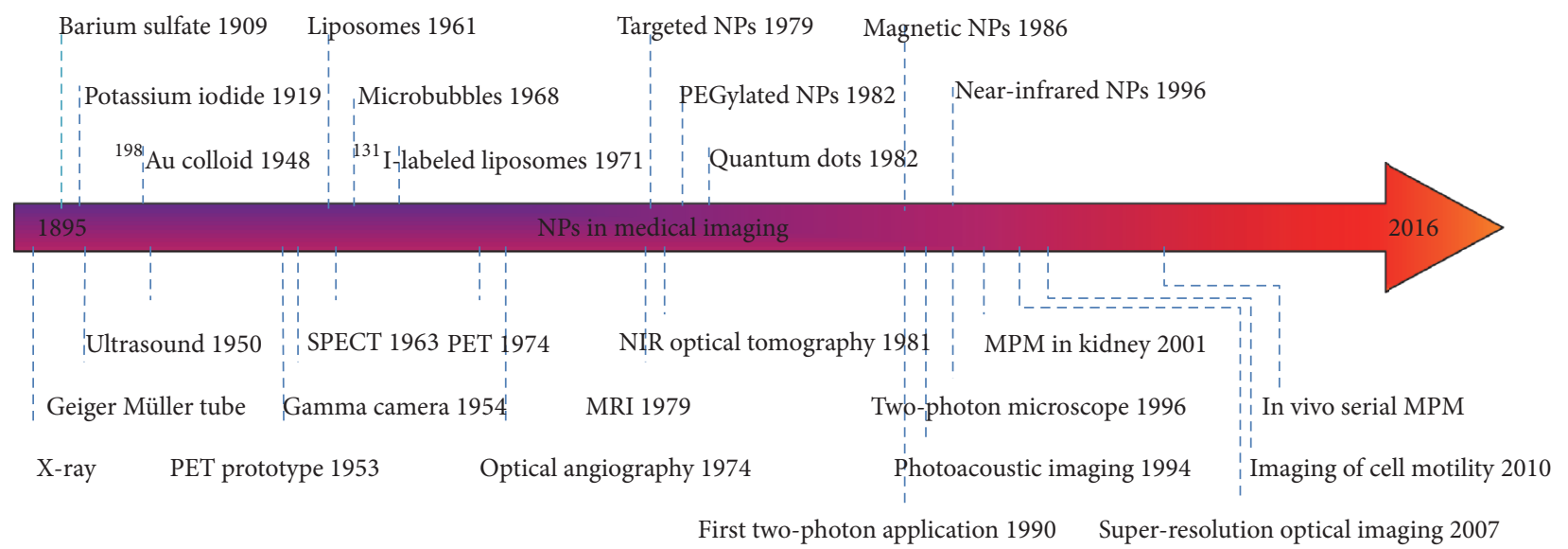

FIGURE 3: Development of NPs as medical imaging contrast agents over the past decade.

Finally, a high-resolution high depth imaging modality can make a revolution in renal disease study. Advanced imaging techniques are just one of the several methods that can be used for early diagnosis of kidney involvement. It has been claimed that accurate analysis of salivary urea can be used as a proper tool in diagnosing of chronic kidney disease [149]. In addition, development of different imaging contrast agents improved the diagnosis accuracy of medical imaging techniques [15]. It can be claimed that the key to further developing the convectional medical imaging modalities, as well as developing entirely new methods, lies in the use of contrast agents. Magnetic particle imaging (MPI) is an new modality in biomedicine that is designed to image the amount and location of super paramagnetic nanoparticles in animals or humans with high spatial and temporal resolution [150]. MPI's decreased image acquisition times foster the making of tomographic images with high spatial and temporal resolution. In addition, the contrast and sensitivity of MPI are improved significantly in compared to other convectional medical imaging modalities, such as MRI, X-ray scans, US, CT, PET, and SPECT [15]. The timeline of development of contrast agents as medical imaging media has been shown in Figure 3.

\section{Competing Interests}

The authors declare that there is no conflict of interests regarding the publication of this manuscript.

\section{References}

[1] P. D. Walker, "The renal biopsy," Archives of Pathology and Laboratory Medicine, vol. 133, no. 2, pp. 181-188, 2009.

[2] R. N. Uppot, M. G. Harisinghani, and D. A. Gervais, "Imagingguided percutaneous renal biopsy: rationale and approach," American Journal of Roentgenology, vol. 194, no. 6, pp. 14431449, 2010.

[3] C. M. Yuan, R. M. Jindal, and K. C. Abbott, "Biopsy: observation time after kidney biopsy: when to discharge?" Nature Reviews Nephrology, vol. 5, no. 10, pp. 552-554, 2009.
[4] S. Mukherjee, M. Jain, and D. S. Scherr, "Multiphoton microscopy in urologic surgery," in Advances in Image-Guided Urologic Surgery, pp. 59-73, Springer, New York, NY, USA, 2015.

[5] M. Gupta and L.-M. Su, "Optical coherence tomography for prostate cancer and beyond," in Advances in Image-Guided Urologic Surgery, pp. 33-40, Springer, Berlin, Germany, 2015.

[6] B. Scheckner, A. Peyser, J. Rube et al., "Diagnostic yield of renal biopsies: a retrospective single center review," BMC Nephrology, vol. 10, no. 1, article 11, 2009.

[7] N. Dhaun, C. O. Bellamy, D. C. Cattran, and D. C. Kluth, "Utility of renal biopsy in the clinical management of renal disease," Kidney International, vol. 85, no. 5, pp. 1039-1048, 2014.

[8] M. Hsu and J. C. Liao, "Endoscopic fluorescence imaging of bladder cancer: photodynamic diagnosis and confocal laser endomicroscopy," in Advances in Image-Guided Urologic Surgery, pp. 3-9, Springer, Berlin, Germany, 2015.

[9] R. Kark and R. Muehrcke, "Biopsy of kidney in prone position," The Lancet, vol. 263, no. 6821, pp. 1047-1049, 1954.

[10] J. W. Ginsburg, J. R. Durant, and L. Mendez, "Percutaneous renal biopsy under direct radiologic direction," JAMA, vol. 181, no. 3, pp. 211-213, 1962.

[11] E. Hasch, "Ultrasound in the investigation of disease of the kidney and urinary tract in children," ACTA PAEDIAT.SCAND., vol. 63, no. 1, pp. 42-48, 1974.

[12] M. Saitoh, H. Watanabe, H. Ohe, S. Tanaka, Y. Itakura, and S. Date, "Ultrasonic real-time guidance for percutaneous puncture," Journal of Clinical Ultrasound, vol. 7, no. 4, pp. 269-272, 1979.

[13] K. Nichols, L. B. Wright, T. Spencer, and W. C. Culp, "Changes in ultrasonographic echogenicity and visibility of needles with changes in angles of insonation," Journal of Vascular and Interventional Radiology, vol. 14, no. 12, pp. 1553-1557, 2003.

[14] J. Comley, "In vivo preclinical imaging," Drug Discovery, vol. 59, 2011.

[15] C. Brede and V. Labhasetwar, "Applications of nanoparticles in the detection and treatment of kidney diseases," Advances in Chronic Kidney Disease, vol. 20, no. 6, pp. 454-465, 2013.

[16] M. H. Pablico-Lansigan, S. F. Situ, and A. C. S. Samia, "Magnetic particle imaging: advancements and perspectives for real-time in vivo monitoring and image-guided therapy," Nanoscale, vol. 5, no. 10, pp. 4040-4055, 2013. 
[17] D. Gaitini, "Imaging acute appendicitis: state of the art," Journal of Clinical Imaging Science, vol. 1, no. 1, Article ID 85778, 2011.

[18] L. Zilberti, O. Bottauscio, and M. Chiampi, "Assessment of exposure to MRI motion-induced fields based on the International Commission on Non-Ionizing Radiation Protection (ICNIRP) guidelines," Magnetic Resonance in Medicine, vol. 76, no. 4, pp. 1291-1300, 2016.

[19] G. Serafini, L. Ongaro, A. Mori et al., "Anesthesia for MRI in the pediatric patient," Minerva Anestesiologica, vol. 71, no. 6, pp. 361-366, 2005.

[20] R. Anderson and A. M. Maga, "A novel procedure for rapid imaging of adult mouse brains with MicroCT using iodinebased contrast," PLoS ONE, vol. 10, no. 11, Article ID e0142974, 2015.

[21] G. McLeod, "Future ultrasound technologies for the perioperative physician," in Perioperative Medicine-Current Controversies, K. Stuart-Smith, Ed., pp. 325-344, Springer International Publishing AG, Cham, Switzerland, 2016.

[22] S. Ghai, G. Eure, V. Fradet et al., "Assessing cancer risk on novel $29 \mathrm{MHz}$ micro-ultrasound images of the prostate: creation of the micro-ultrasound protocol for prostate risk identification," The Journal of Urology, vol. 196, no. 2, pp. 562-569, 2016.

[23] H. Khosroshahi, M. Tarzamni, M. Gojazadeh, and A. Bahluli, "Color Doppler findings in transplanted kidneys and remnant kidneys of donors 6 to 12 months after kidney transplantation," Transplantation Proceedings, vol. 39, no. 4, pp. 816-818, 2007.

[24] S. J. Parekatti and M. Moran, Instruments. Telemicrosurgery, Springer, 2013.

[25] N. Heyder and G. Lux, "Malignant lesions of the upper gastrointestinal tract," Scandinavian Journal of Gastroenterology, vol. 21, no. 123 , pp. 47-51, 1986.

[26] B. Liu, F. Liang, L.-P. Gu et al., "Renal blood perfusion in GK rats using targeted contrast enhanced ultrasonography," Asian Pacific Journal of Tropical Medicine, vol. 8, no. 8, pp. 668-673, 2015.

[27] A. Parthipun and J. Pilcher, "Renal transplant assessment: sonographic imaging," Ultrasound Clinics, vol. 5, no. 3, pp. 379399, 2010.

[28] D. O. Cosgrove and K. E. Chan, "Renal transplants: what ultrasound can and cannot do," Ultrasound Quarterly, vol. 24, no. 2, pp. 77-87, 2008.

[29] H. Malhi, E. G. Grant, and V. Duddalwar, "Contrast-enhanced ultrasound of the liver and kidney," Radiologic Clinics of North America, vol. 52, no. 6, pp. 1177-1190, 2014.

[30] K. Ghabili, H. T. Khosroshahi, A. Shakeri, R. S. Tubbs, A. Bahluli, and M. M. Shoja, "Can doppler ultrasonographic indices of the renal artery predict the presence of supernumerary renal arteries?" Transplantation Proceedings, vol. 41, no. 7, pp. 2731-2733, 2009.

[31] K. Ansarin, A. S. Bavil, K. Ghabili et al., "Are Doppler ultrasonography parameters symmetric between the right and left kidney?" International Journal of General Medicine, vol. 3, pp. 371-373, 2010.

[32] H. T. Khosroshahi, H. K. Heris, N. Makhdami et al., “Timedependent Doppler ultrasonographic findings in transplanted kidneys from living donors: a 5-year follow-up study," Transplantation Proceedings, vol. 43, no. 2, pp. 482-484, 2011.

[33] E. Stride, "Physical principles of microbubbles for ultrasound imaging and therapy," Cerebrovascular Diseases, vol. 27, supplement 2, pp. 1-13, 2009.
[34] E. Stride, Physical Principles of Microbubbles for Ultrasound Imaging and Therapy, vol. 36 of Translational Neurosonology, Karger, 2014.

[35] P. Voisin, E. J. Ribot, S. Miraux et al., "Use of lanthanide-grafted inorganic nanoparticles as effective contrast agents for cellular uptake imaging," Bioconjugate Chemistry, vol. 18, no. 4, pp. 1053-1063, 2007.

[36] S. M. Dicker, Colloidal Science of Ultrasound Contrast Agents, Drexel University, 2012.

[37] B. Geers, O. De Wever, J. Demeester, M. Bracke, S. C. De Smedt, and I. Lentacker, "Targeted liposome-loaded microbubbles for cell-specific ultrasound-triggered drug delivery," Small, vol. 9, no. 23, pp. 4027-4035, 2013.

[38] K. Tsuruoka, T. Yasuda, K. Koitabashi et al., "Evaluation of renal microcirculation by contrast-enhanced ultrasound with sonazoid $^{\mathrm{TM}}$ as a contrast agent: comparison between normal subjects and patients with chronic kidney disease," International Heart Journal, vol. 51, no. 3, pp. 176-182, 2010.

[39] S. A. Peyman, J. R. McLaughlan, R. H. Abou-Saleh et al., "Onchip preparation of nanoscale contrast agents towards highresolution ultrasound imaging," Lab on a Chip, vol. 16, no. 4, pp. 679-687, 2016.

[40] L. O. Johansson, A. Bjrnerud, H. K. Ahlström, D. L. Ladd, and D. K. Fujii, "A targeted contrast agent for magnetic resonance imaging of thrombus: implications of spatial resolution," Journal of Magnetic Resonance Imaging, vol. 13, no. 4, pp. 615-618, 2001.

[41] J. R. Lindner, P. A. Dayton, M. P. Coggins et al., "Noninvasive imaging of inflammation by ultrasound detection of Phagocytosed microbubbles," Circulation, vol. 102, no. 5, pp. 531-538, 2000.

[42] J. R. Lindner, "Microbubbles in medical imaging: current applications and future directions," Nature Reviews Drug Discovery, vol. 3, no. 6, pp. 527-533, 2004.

[43] A. S. Fulcher, A. V. Proto, and H. Jolles, "Cystic teratoma of the mediastinum: demonstration of fat/fluid level," American Journal of Roentgenology, vol. 154, no. 2, pp. 259-260, 1990.

[44] J. Ehling, J. Bábíčková, F. Gremse et al., "Quantitative microcomputed tomography imaging of vascular dysfunction in progressive kidney diseases," Journal of the American Society of Nephrology, vol. 27, no. 2, pp. 520-532, 2016.

[45] C. Theodorakou and M. J. Farquharson, "Human soft tissue analysis using $\mathrm{x}$-ray or gamma-ray techniques," Physics in Medicine and Biology, vol. 53, no. 11, pp. R111-R149, 2008.

[46] L. Schoeman, P. Williams, A. du Plessis, and M. Manley, "X-ray micro-computed tomography $(\mu \mathrm{CT})$ for non-destructive characterisation of food microstructure," Trends in Food Science \& Technology, vol. 47, pp. 10-24, 2016.

[47] V. Cnudde and M. N. Boone, "High-resolution X-ray computed tomography in geosciences: a review of the current technology and applications," Earth-Science Reviews, vol. 123, pp. 1-17, 2013.

[48] H. Lusic and M. W. Grinstaff, "X-ray-computed tomography contrast agents," Chemical Reviews, vol. 113, no. 3, pp. 1641-1666, 2013.

[49] S. Artul and A. Yamini, "Motion artefact in multidetector CT in a child with severe chest injury resembling serious pathology," Emergency Medicine Journal, vol. 31, no. 9, p. 744, 2013.

[50] B. M. Khoury, E. M. R. Bigelow, L. M. Smith et al., "The use of nano-computed tomography to enhance musculoskeletal research," Connective Tissue Research, vol. 56, no. 2, pp. 106-119, 2015. 
[51] N. Lee, S. H. Choi, and T. Hyeon, "Nano-sized CT contrast agents," Advanced Materials, vol. 25, no. 19, pp. 2641-2660, 2013.

[52] W. He, K. Ai, and L. Lu, "Nanoparticulate X-ray CT contrast agents," Science China Chemistry, vol. 58, no. 5, pp. 753-760, 2015.

[53] K. Homma, T. Yoshida, M. Yamashita, K. Hayashida, M. Hayashi, and S. Hori, "Inhalation of hydrogen gas is beneficial for preventing contrast-induced acute kidney injury in rats," Nephron Experimental Nephrology, vol. 128, no. 3-4, pp. 116-122, 2014.

[54] G. V. A. O’Reilly and G. Bryan, “The double contrast barium meal-a simplification," British Journal of Radiology, vol. 47, no. 560, pp. 482-483, 1974.

[55] Y. Jin, C. Jia, S.-W. Huang, M. O’Donnell, and X. Gao, "Multifunctional nanoparticles as coupled contrast agents," Nature communications, vol. 1, article no. 41, 2010.

[56] J. T. Bushberg, J. A. Seibert, E. M. Leidholdt, J. M. Boone, and E. J. Goldschmidt, "The essential physics of medical imaging," Medical Physics, vol. 30, no. 7, p. 1936, 2003.

[57] A. W. J. M. Glaudemans, A. M. Quintero, and A. Signore, "PET/MRI in infectious and inflammatory diseases: will it be a useful improvement?" European Journal of Nuclear Medicine and Molecular Imaging, vol. 39, no. 5, pp. 745-749, 2012.

[58] D. Yoo, J.-H. Lee, T.-H. Shin, and J. Cheon, "Theranostic magnetic nanoparticles," Accounts of Chemical Research, vol. 44, no. 10, pp. 863-874, 2011.

[59] J. M. Janjic and M. Bai, "Design and development of theranostic nanomedicines," in Nanotechnology for Biomedical Imaging and Diagnostics, pp. 429-465, John Wiley \& Sons, 2015.

[60] S. Daneshvar and H. Ghassemian, "MRI and PET image fusion by combining IHS and retina-inspired models," Information Fusion, vol. 11, no. 2, pp. 114-123, 2010.

[61] B. K. Nobariyan, S. Daneshvar, and A. Foroughi, "A new MRI and PET image fusion algorithm based on pulse coupled neural network," in Proceedings of the 22nd Iranian Conference on Electrical Engineering (ICEE '14), pp. 1950-1955, IEEE, Tehran, Iran, May 2014.

[62] M. V. Irazabal, P. K. Mishra, V. E. Torres, and S. I. Macura, "Use of ultra-high field MRI in small rodent models of polycystic kidney disease for in vivo phenotyping and drug monitoring," Journal of Visualized Experiments, Article ID e52757, 2015.

[63] A. R. Guimaraes, S. Tabatabei, D. Dahl, W. S. McDougal, R. Weissleder, and M. G. Harisinghani, "Pilot study evaluating use of lymphotrophic nanoparticle-enhanced magnetic resonance imaging for assessing lymph nodes in renal cell cancer," Urology, vol. 71, no. 4, pp. 708-712, 2008.

[64] M. E. Ladd, E. R. Gizewski, and D. Timmann, "Clinical neuro and beyond," in High-Field MR Imaging, Medical Radiology, pp. 151-173, Springer, Heidelberg, Germany, 2012.

[65] S. Saito, Y. Mori, Y. Yoshioka, and K. Murase, "High-resolution ex vivo imaging in mouse spinal cord using micro-CT with 11.7T-MRI and myelin staining validation," Neuroscience Research, vol. 73, no. 4, pp. 337-340, 2012.

[66] H. Shokrollahi, “Contrast agents for MRI," Materials Science and Engineering: C, vol. 33, no. 8, pp. 4485-4497, 2013.

[67] S. Blyth, A. Blakeborough, M. Peterson, I. C. Cameron, and A. W. Majeed, "Sensitivity of magnetic resonance imaging in the detection of colorectal liver metastases," The Annals of the Royal College of Surgeons of England, vol. 90, no. 1, pp. 25-28, 2008.

[68] D. W. McRobbie, E. A. Moore, M. J. Graves, and M. R. Prince, MRI: From Picture to Proton, Cambridge University Press, Cambridge, UK, 2003.
[69] S.-K. Jo, X. Hu, H. Kobayashi et al., "Detection of inflammation following renal ischemia by magnetic resonance imaging," Kidney International, vol. 64, no. 1, pp. 43-51, 2003.

[70] K. Kalantarinia, "Novel imaging techniques in acute kidney injury," Current Drug Targets, vol. 10, no. 12, pp. 1184-1189, 2009.

[71] "Surface modified gadolinium phosphate nanoparticles as MRI contrast agents," in Proceedings of the APS March Meeting 2012, M. F. Dumont, C. Baligand, E. S. Knowles, M. W. Meisel, G. A. Walter, and D. R. Talham, Eds., Boston, Mass, USA, March 2012.

[72] F. R. Korosec, "Basic principles of MRI and MR angiography," in Magnetic Resonance Angiography, pp. 3-38, Springer, New York, NY, USA, 2012.

[73] A. S. Wadajkar, T. Kadapure, Y. Zhang, W. Cui, K. T. Nguyen, and J. Yang, "Dual-imaging enabled cancer-targeting nanoparticles," Advanced Healthcare Materials, vol. 1, no. 4, pp. 450-456, 2012.

[74] H. Kobayashi, S.-K. Jo, S. Kawamoto et al., "Polyamine dendrimer-based MRI contrast agents for functional kidney imaging to diagnose acute renal failure," Journal of Magnetic Resonance Imaging, vol. 20, no. 3, pp. 512-518, 2004.

[75] J. W. Dear, H. Kobayashi, M. W. Brechbiel, and R. A. Star, "Imaging acute renal failure with polyamine dendrimer-based MRI contrast agents," Nephron Clinical Practice, vol. 103, no. 2, pp. c45-c49, 2006.

[76] P. Caravan, "Physicochemical principles of MR contrast agents," in Molecular and Cellular MR Imaging, pp. 13-36, CRC Press, 2007.

[77] L. Zhang, F. Yu, A. J. Cole et al., "Gum arabic-coated magnetic nanoparticles for potential application in simultaneous magnetic targeting and tumor imaging," The AAPS Journal, vol. 11, no. 4, pp. 693-699, 2009.

[78] G.-P. Yan, L. Robinson, and P. Hogg, "Magnetic resonance imaging contrast agents: overview and perspectives," Radiography, vol. 13, no. 1, pp. e5-e19, 2007.

[79] L. S. Politi, "MR-based imaging of neural stem cells," Neuroradiology, vol. 49, no. 6, pp. 523-534, 2007.

[80] T. Allkemper, C. Bremer, L. Matuszewski, W. Ebert, and P. Reimer, "Contrast-enhanced blood-pool MR angiography with optimized iron oxides: effect of size and dose on vascular contrast enhancement in rabbits," Radiology, vol. 223, no. 2, pp. 432-438, 2002.

[81] B. Godin, J. H. Sakamoto, R. E. Serda, A. Grattoni, A. Bouamrani, and M. Ferrari, "Emerging applications of nanomedicine for the diagnosis and treatment of cardiovascular diseases," Trends in Pharmacological Sciences, vol. 31, no. 5, pp. 199-205, 2010.

[82] S. Venkatraman, "Has nanomedicine lived up to its promise?" Nanotechnology, vol. 25, no. 37, Article ID 372501, 2014.

[83] M. H. Rosner and M. Auerbach, "Ferumoxytol for the treatment of iron deficiency," Expert Review of Hematology, vol. 4, no. 4, pp. 399-406, 2011.

[84] K. B. Narayanan and N. Sakthivel, "Nanotechnology and cardiovascular diseases," in Cardiovascular Diseases: Nutritional and Therapeutic Interventions, chapter 14, p. 255, CRC Press, 2013.

[85] J. D. Collins and T. Scanlon, "Lower extremity peripheral arterial disease," in Magnetic Resonance Angiography, pp. 319336, Springer, New York, NY, USA, 2012.

[86] E. Kanal, K. Maravilla, and H. A. Rowley, "Gadolinium contrast agents for CNS imaging: current concepts and clinical evidence," American Journal of Neuroradiology, vol. 35, no. 12, pp. 2215-2226, 2014. 
[87] S. K. Morcos, "Extracellular gadolinium contrast agents: differences in stability," European Journal of Radiology, vol. 66, no. 2, pp. 175-179, 2008.

[88] D. Koktysh, V. Bright, and W. Pham, "Fluorescent magnetic hybrid nanoprobe for multimodal bioimaging," Nanotechnology, vol. 22, no. 27, Article ID 275606, 2011.

[89] B. A. Lutey, S. S. Lefrak, J. D. Cooper et al., "Hyperpolarized 3helium magnetic resonance imaging: safety considerations and physiologic monitoring," CHEST Journal, vol. 132, pp. 525b526b, 2007.

[90] G. J. Strijkers, W. J. M. Mulder, G. A. F. van Tilborg, and K. Nicolay, "MRI contrast agents: current status and future perspectives," Anti-Cancer Agents in Medicinal Chemistry, vol. 7, no. 3, pp. 291-305, 2007.

[91] Z. Zhen and J. Xie, "Development of manganese-based nanoparticles as contrast probes for magnetic resonance imaging," Theranostics, vol. 2, no. 1, pp. 45-54, 2012.

[92] L. Q. Chen, C. Howison, J. Jeffery, I. Robey, and M. Pagel, "Measuring extracellular $\mathrm{pH}$ within in vivo tumors using acidoCEST MRI," Cancer Research, vol. 73, supplement 8, p. 2676, 2013.

[93] W. Krause, A. Schönborn, and K. Rupp, "CT imaging with iopromide liposomes in a rabbit model," Journal of Liposome Research, vol. 21, no. 3, pp. 229-236, 2011.

[94] "In-vivo human kidney $\mathrm{pH}$ mapping at $3 \mathrm{~T}$ using timeinterleaved parallel RF transmission CEST," in Proceedings of the 20th Annual Meeting and Exhibition, I. Dimitrov, M. Takahashi, K. Sagiyama, A. D. Sherry, and J. Keupp, Eds., International Society for Magnetic Resonance in Medicine, May 2012.

[95] G. L. Wolf, R. L. Arenson, and A. P. Cross, "A prospective trial of ionic vs nonionic contrast agents in routine clinical practice: comparison of adverse effects," American Journal of Roentgenology, vol. 152, no. 5, pp. 939-944, 1989.

[96] D. M. Biko, D. G. Rosenbaum, and S. A. Anupindi, "Ultrasound features of pediatric Crohn disease: a guide for case interpretation," Pediatric Radiology, vol. 45, no. 10, pp. 1557-1566, 2015.

[97] D. E. Luciano, C. Exacoustos, D. A. Johns, and A. A. Luciano, "Can hysterosalpingo-contrast sonography replace hysterosalpingography in confirming tubal blockage after hysteroscopic sterilization and in the evaluation of the uterus and tubes in infertile patients?" American Journal of Obstetrics and Gynecology, vol. 204, no. 1, pp. 79.e1-79.e5, 2011.

[98] Profile AR, "AFO 150 imagent, imavist," Drugs, vol. 3, no. 2, pp. 116-118, 2002.

[99] M. J. Hackl, J. L. Burford, K. Villanueva et al., "Tracking the fate of glomerular epithelial cells in vivo using serial multiphoton imaging in new mouse models with fluorescent lineage tags," Nature Medicine, vol. 19, no. 12, pp. 1661-1666, 2013.

[100] T. Zhang and H. Cui, Eds., Carbon Nanoparticles in Photoacoustic Imaging, SPIE, 2015.

[101] D. P. Cormode, P. A. Jarzyna, W. J. M. Mulder, and Z. A. Fayad, "Modified natural nanoparticles as contrast agents for medical imaging," Advanced Drug Delivery Reviews, vol. 62, no. 3, pp. 329-338, 2010.

[102] S. S. Caetano, T. Teixeira, and C. E. Tadokoro, "Intravital imaging of the mouse thymus using 2-photon microscopy," JoVE (Journal of Visualized Experiments), no. 59, article e3504, 2012.

[103] C. Leng and J. Tian, "Mathematical method in optical molecular imaging," Science China Information Sciences, vol. 58, no. 3, 2015.

[104] C. Piazza, F. Del Bon, A. Paderno et al., "The diagnostic value of narrow band imaging in different oral and oropharyngeal subsites," European Archives of Oto-Rhino-Laryngology, vol. 273, no. 10, pp. 3347-3353, 2016.

[105] J. Peti-Peterdi, J. L. Burford, and M. J. Hackl, "The first decade of using multiphoton microscopy for high-power kidney imaging," American Journal of Physiology-Renal Physiology, vol. 302, no. 2, pp. F227-F233, 2012.

[106] A. Taruttis, J. Claussen, D. Razansky, and V. Ntziachristos, "Motion clustering for deblurring multispectral optoacoustic tomography images of the mouse heart," Journal of Biomedical Optics, vol. 17, no. 1, Article ID 016009, 2012.

[107] A. Taruttis and V. Ntziachristos, "Advances in real-time multispectral optoacoustic imaging and its applications," Nature Photonics, vol. 9, no. 4, pp. 219-227, 2015.

[108] R. K. Wang, Y. He, and V. V. Tuchin, "Effect of dehydration on optical clearing and OCT imaging contrast after impregnation of biological tissue with biochemical agents," in Proceedings of the Progress in Biomedical Optics and Imaging-Coherence Domain Optical Methods and Optical Coherence Tomography in Biomedicine VIII, International Society for Optics and Photonics, San Jose, Calif, USA, 2004.

[109] W. Li and X. Chen, "Gold nanoparticles for photoacoustic imaging," Nanomedicine, vol. 10, no. 2, pp. 299-320, 2015.

[110] J. Peti-Peterdi, K. Kidokoro, and A. Riquier-Brison, "Novel in vivo techniques to visualize kidney anatomy and function," Kidney International, vol. 88, no. 1, pp. 44-51, 2015.

[111] H. F. Zhang, K. Maslov, G. Stoica, and L. V. Wang, "Functional photoacoustic microscopy for high-resolution and noninvasive in vivo imaging," Nature Biotechnology, vol. 24, no. 7, pp. 848851, 2006.

[112] S. Arridge, P. Beard, M. Betcke et al., "Accelerated highresolution photoacoustic tomography via compressed sensing," Physics in Medicine and Biology, vol. 61, no. 24, pp. 8908-8940, 2016.

[113] I.-T. Ho, J. L. Sessler, S. S. Gambhir, and J. V. Jokerst, "Parts per billion detection of uranium with a porphyrinoid-containing nanoparticle and in vivo photoacoustic imaging," Analyst, vol. 140, no. 11, pp. 3731-3737, 2015.

[114] K. Maslov, G. Stoica, and L. V. Wang, "In vivo dark-field reflection-mode photoacoustic microscopy," Optics Letters, vol. 30, no. 6, pp. 625-627, 2005.

[115] J.-M. Yang, C. Favazza, R. Chen et al., "Simultaneous functional photoacoustic and ultrasonic endoscopy of internal organs in vivo," Nature Medicine, vol. 18, no. 8, pp. 1297-1302, 2012.

[116] A. Meadway, S. H. H. Darbrazi, G. Dobre, R. B. Rosen, and A. G. Podoleanu, "A rapid method of measuring dispersion in low coherence interferometry and optical coherence tomography systems," Journal of Optics A, vol. 12, no. 1, Article ID 015302, 2010.

[117] N. Hanna, D. Saltzman, D. Mukai et al., “Two-dimensional and 3-dimensional optical coherence tomographic imaging of the airway, lung, and pleura," The Journal of Thoracic and Cardiovascular Surgery, vol. 129, no. 3, pp. 615-622, 2005.

[118] P. M. Andrews, Y. Chen, J. Wierwille et al., "Using OCT to predict post-transplant renal function," in Proceedings of the Photonic Therapeutics and Diagnostics IX, vol. 8565, San Francisco, Calif, USA, February 2013.

[119] J. G. Fujimoto, "Optical and acoustical imaging of biological media," Comptes Rendus de l'Académie des Sciences, Paris, vol. 2, pp. 1099-1111, 2001.

[120] M. Bus, D. de Bruin, T. M. de Reijke, and J. de la Rosette, "Optical coherence tomography in bladder cancer," in Advances in Image-Guided Urologic Surgery, pp. 21-32, Springer, 2015. 
[121] H. Kitabata and T. Akasaka, "Recent developments in intracoronary optical coherence tomography imaging," Imaging in Medicine, vol. 3, no. 3, pp. 299-311, 2011.

[122] V. V. Sapozhnikova, V. A. Kamenskii, and R. V. Kuranov, "Visualization of plant tissues by optical coherence tomography," Russian Journal of Plant Physiology, vol. 50, no. 2, pp. 282-286, 2003.

[123] B. E. Bouma, G. J. Tearney, C. C. Compton, and N. S. Nishioka, "High-resolution imaging of the human esophagus and stomach in vivo using optical coherence tomography," Gastrointestinal Endoscopy, vol. 51, no. 4, pp. 467-474, 2000.

[124] P. Matousek and N. Stone, "Development of deep subsurface Raman spectroscopy for medical diagnosis and disease monitoring," Chemical Society Reviews, vol. 45, no. 7, pp. 1794-1802, 2016.

[125] M. S. Bergholt, W. Zheng, K. Lin et al., "Characterizing variability of in vivo Raman spectroscopic properties of different anatomical sites of normal colorectal tissue towards cancer diagnosis at colonoscopy," Analytical Chemistry, vol. 87, no. 2, pp. 960-966, 2015.

[126] J. Sharpe, "Optical projection tomography," Annual Review of Biomedical Engineering, vol. 6, no. 1, pp. 209-228, 2004.

[127] L. N. Taylor, W. M. Townsend, H. Gan Heng, J. Stiles, and G. E. Moore, "Comparison of ultrasound biomicroscopy and standard ocular ultrasonography for detection of canine uveal cysts," American Journal of Veterinary Research, vol. 76, no. 6, pp. 540-546, 2015.

[128] N. Thakur, R. Singh, S. Kaur, A. Kumar, S. Phuljhele, and J. Sukhija, "Ultrasound biomicroscopy in strabismus surgery: efficacy in postoperative assessment of horizontal muscle insertions," Strabismus, vol. 23, no. 2, pp. 73-79, 2015.

[129] E. Ünsal, K. Eltutar, I. Muftuoglu, T. A. Akcetin, and Y. Acar, "Ultrasound biomicroscopy in patients with unilateral pseudoexfoliation," International Journal of Ophthalmology, vol. 8, no. 4, pp. 754-758, 2015.

[130] O. Stachs, A. Zhivov, R. Kraak, J. Stave, and R. Guthoff, "In vivo three-dimensional confocal laser scanning microscopy of the epithelial nerve structure in the human cornea," Graefe's Archive for Clinical and Experimental Ophthalmology, vol. 245, no. 4, pp. 569-575, 2007.

[131] J.-Y. Jang and M. Cho, "Image visualization of photon counting confocal microscopy using statistical estimation," OptikInternational Journal for Light and Electron Optics, vol. 127, no. 2, pp. 844-847, 2016.

[132] G. D. Kymionis, V. F. Diakonis, M. M. Shehadeh, A. I. Pallikaris, and I. G. Pallikaris, "Anterior segment applications of in vivo confocal microscopy," Seminars in Ophthalmology, vol. 30, no. 4, pp. 243-251, 2015.

[133] S. Di Staso and M. Ciancaglini, "In vivo three-dimensional analysis of conjunctival epithelial microcysts in glaucoma," Journal of Clinical \& Experimental Ophthalmology, vol. 7, article 524, 2016.

[134] A. Briens, M. Gauberti, J. Parcq, J. Montaner, D. Vivien, and S. M. de Lizarrondo, "Nano-zymography using laser-scanning confocal microscopy unmasks proteolytic activity of cellderived microparticles," Theranostics, vol. 6, no. 5, pp. 610-626, 2016.

[135] H. W. Herr, "Narrow band imaging for urothelial cancer," in Advances in Image-Guided Urologic Surgery, pp. 11-19, Springer, 2015.

[136] L. Dinesen, T. J. Chua, and A. J. Kaffes, "Meta-analysis of narrow-band imaging versus conventional colonoscopy for adenoma detection," Gastrointestinal Endoscopy, vol. 75, no. 3, pp. 604-611, 2012.

[137] S. A. Ritchie, B. Chitou, Q. Zheng et al., "Pancreatic cancer serum biomarker PC-594: diagnostic performance and comparison to CA19-9," World Journal of Gastroenterology, vol. 21, no. 21, pp. 6604-6612, 2015.

[138] G. Wu, Fluorescence Image-Guided Robotic Surgery, Advances in Image-Guided Urologic Surgery, Springer, Berlin, Germany, 2015.

[139] N. Gonzalo, G. J. Tearney, P. W. Serruys et al., "Secondgeneration optical coherence tomography in clinical practice. High-speed data acquisition is highly reproducible in patients undergoing percutaneous coronary intervention," Revista Espanola de Cardiologia, vol. 63, no. 8, pp. 893-903, 2010.

[140] N. J. Hangiandreou, "AAPM/RSNA physics tutorial for residents: topics in US: B-mode US: basic concepts and new technology," Radiographics, vol. 23, no. 4, pp. 1019-1033, 2003.

[141] M. J. Boot, C. H. Westerberg, J. Sanz-Ezquerro et al., "In vitro whole-organ imaging: 4D quantification of growing mouse limb buds," Nature Methods, vol. 5, no. 7, pp. 609-612, 2008.

[142] R. Sheth, U. Mahmood, and A. Samir, "Optical Biopsy Needle and Endoscope System," US Patent 20,160,030,022, 2016.

[143] O. Ukimura, K. Okihara, K. Kamoi, Y. Naya, A. Ochiai, and T. Miki, "Intraoperative ultrasonography in an era of minimally invasive urology," International Journal of Urology, vol. 15, no. 8, pp. 673-680, 2008.

[144] A. C. Mues, Z. Okhunov, K. Badani, M. Gupta, and J. Landman, "Intraoperative evaluation of renal blood flow during laparoscopic partial nephrectomy with a novel doppler system," Journal of Endourology, vol. 24, no. 12, pp. 1953-1956, 2010.

[145] S. Porten, R. Vikram, and S. F. Matin, "Endoluminal ultrasonography," in Advances in Image-Guided Urologic Surgery, pp. 131138, Springer, 2015.

[146] L. Cheng, S. D. Shen, S. Shi et al., "FeSe $e_{2}$-decorated $\mathrm{Bi}_{2} \mathrm{Se}_{3}$ nanosheets fabricated via cation exchange for chelator-free ${ }^{64} \mathrm{Cu}$-labeling and multimodal image-guided photothermalradiation therapy," Advanced Functional Materials, vol. 26, no. 13, pp. 2185-2197, 2016.

[147] Y. Luo, S.-Z. Zhu, H. Ye, H.-W. Mao, and C.-M. Wang, “Tunable optical properties with planar metamaterial lens," Journal of Modern Optics, vol. 62, no. 12, pp. 971-977, 2015.

[148] R. Kanawade, B. Lengenfelder, T. M. Menezes et al., "Improved cancer diagnostics by different image processing techniques on OCT images," in Proceedings of the SPIE Optical Coherence Imaging Techniques and Imaging in Scattering Media, vol. 9541, Optical Society of America, Bern, Switzerland, 2015.

[149] M. E. Zúñiga, L. O. Estremadoyro, C. P. León, J. A. Huapaya, and J. A. Cieza, "Validation of the salivary urea test as a method to diagnose chronic kidney disease," Journal of Nephrology, vol. 25, no. 3, pp. 431-436, 2012.

[150] D. Eberbeck, F. Wiekhorst, S. Wagner, and L. Trahms, "How the size distribution of magnetic nanoparticles determines their magnetic particle imaging performance," Applied Physics Letters, vol. 98, no. 18, Article ID 182502, 2011. 


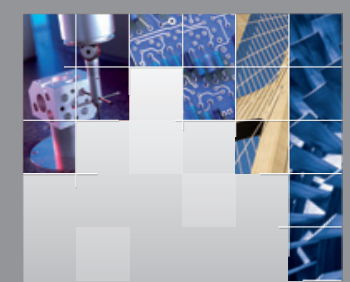

\section{Enfincering}
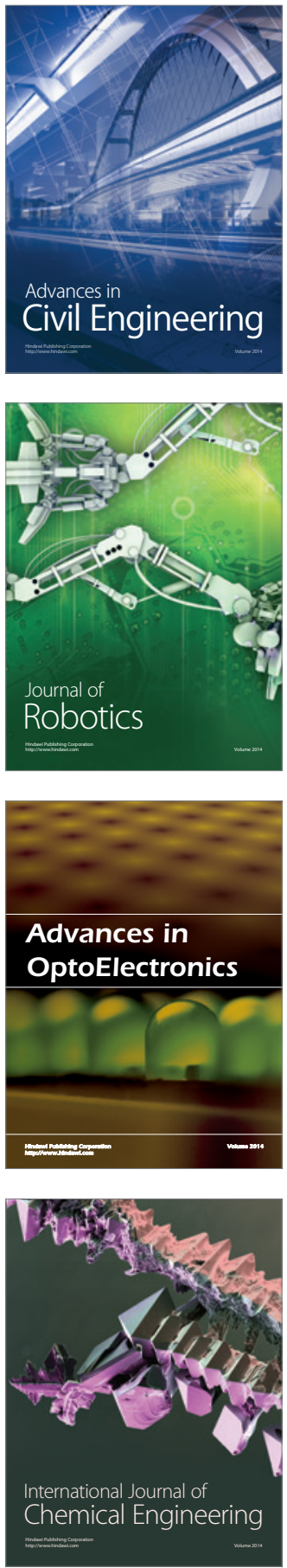

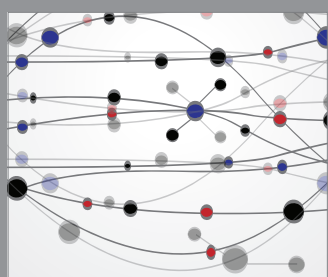

The Scientific World Journal

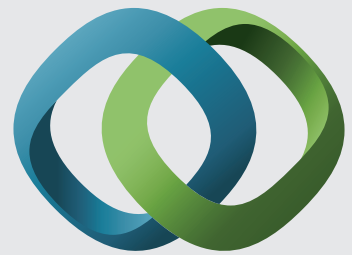

\section{Hindawi}

Submit your manuscripts at

https://www.hindawi.com
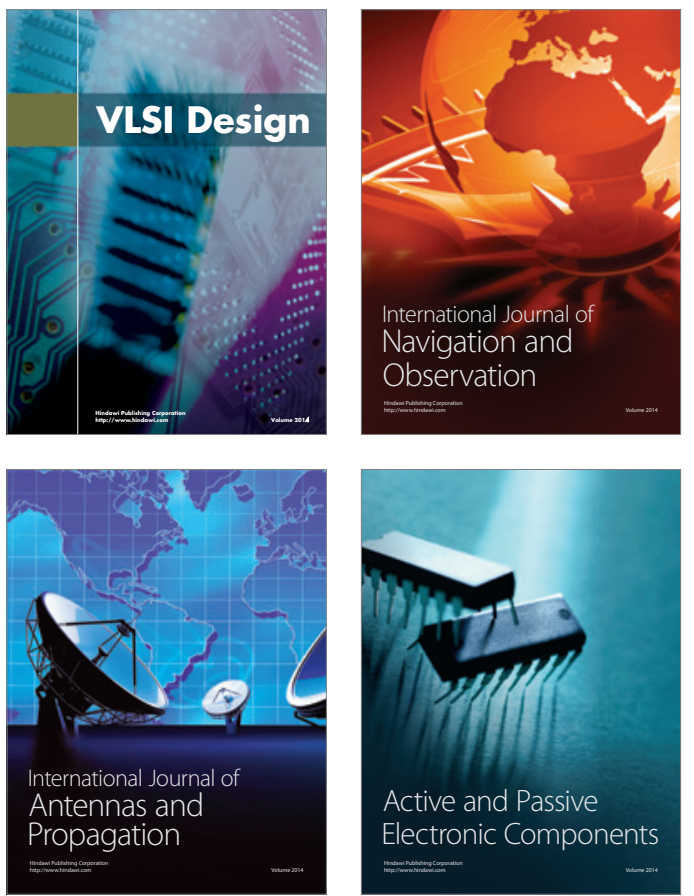
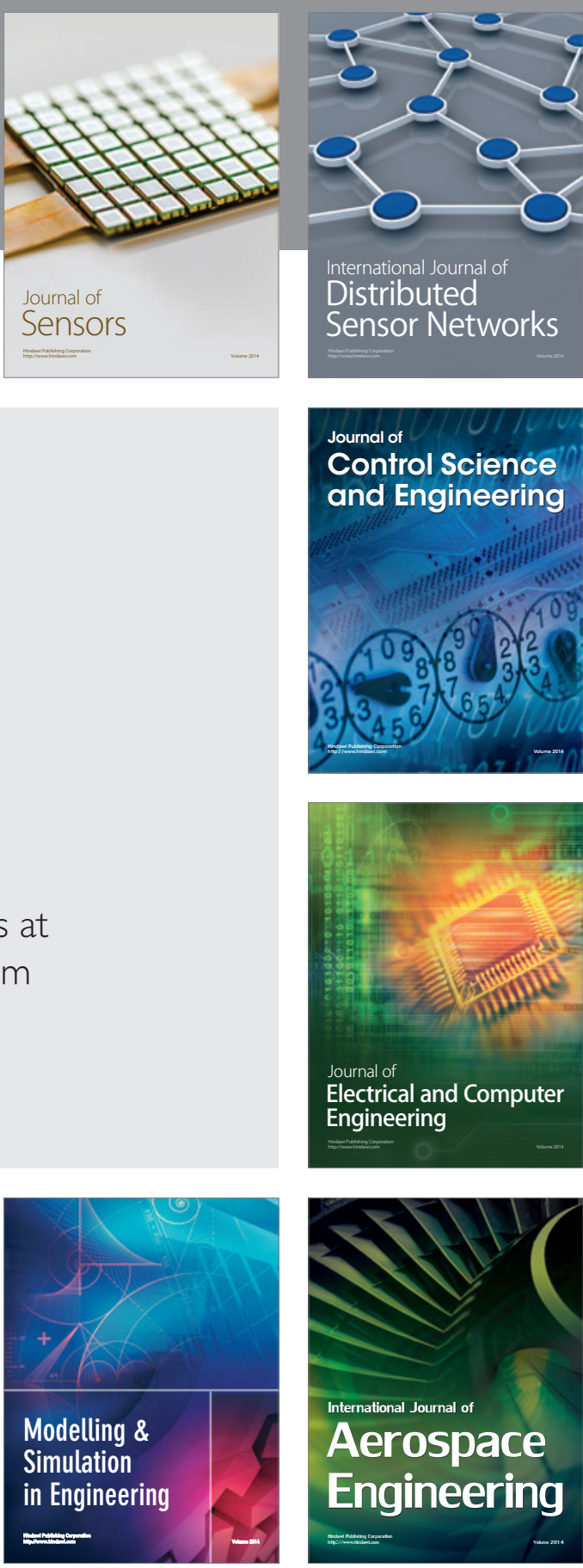

International Journal of

Distributed

Sensor Networks

$-$

Joumal of

Control Science

and Engineering
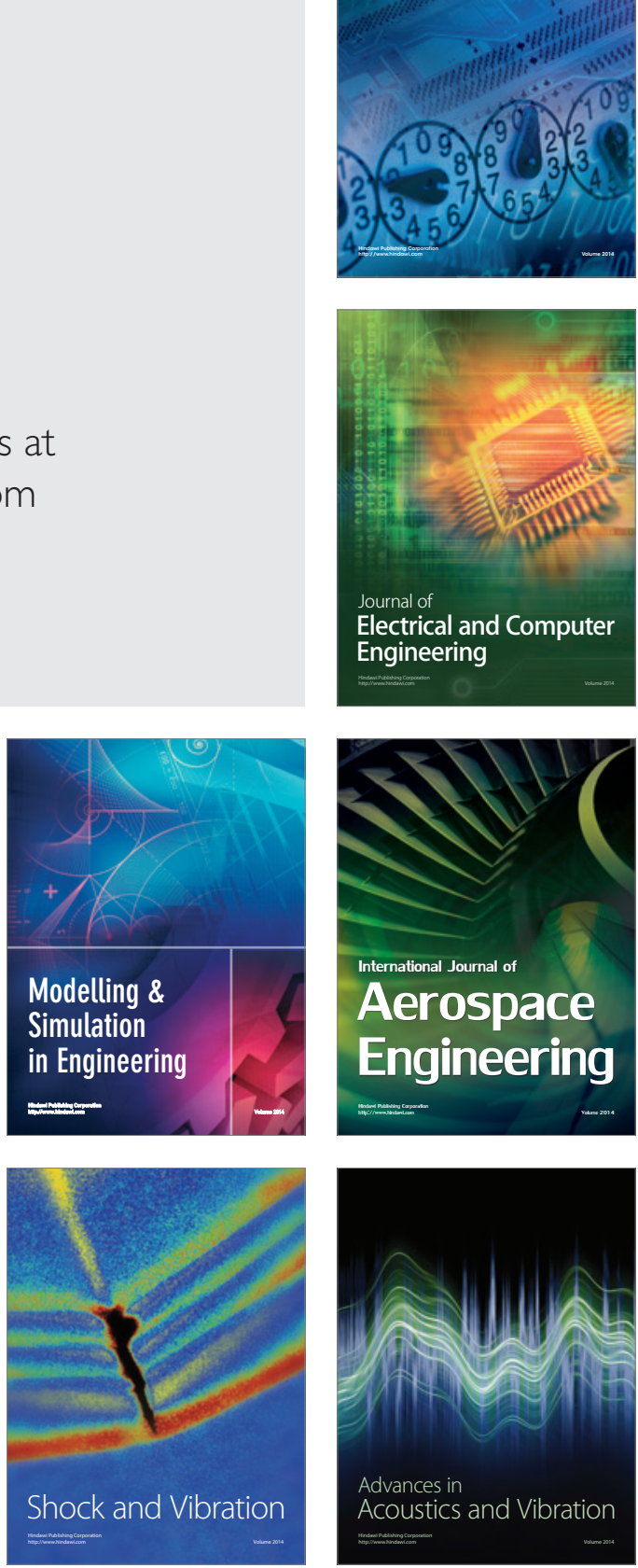